\title{
International Unit per Gram
}

National Cancer Institute

\section{Source}

National Cancer Institute. International Unit per Gram. NCI Thesaurus. Code C70493.

A unit of measure of a quantity of substance per unit mass, expressed as the quantity of substance in International Units, divided by the mass of the substance in grams. It is also used as a dose calculation unit expressed in International Units of biological activity per one gram of body mass. 